\title{
Research Progress on Shear Characteristics of Rock Joints under Constant Normal Stiffness Boundary Conditions
}

\author{
Guansheng Han $\left(\mathbb{D},{ }^{1}\right.$ Fei Xiong $\mathbb{D}^{\mathbb{D}},{ }^{2}$ Yu Zhou $\mathbb{D}^{1},{ }^{1}$ Leibo Song $\mathbb{D}^{1},{ }^{1}$ and Xingkai Wang $\mathbb{D}^{1}$ \\ ${ }^{1}$ Key Laboratory of Rock Mechanics and Geohazards of Zhejiang Province, Shaoxing University, Shaoxing, \\ Zhejiang 312000, China \\ ${ }^{2}$ School of Civil Engineering, Chongqing University, Chongqing 400045, China \\ Correspondence should be addressed to Fei Xiong; xiongfeiss@126.com
}

Received 13 July 2021; Accepted 16 August 2021; Published 2 September 2021

Academic Editor: Xuepeng Zhang

Copyright (c) 2021 Guansheng Han et al. This is an open access article distributed under the Creative Commons Attribution License, which permits unrestricted use, distribution, and reproduction in any medium, provided the original work is properly cited.

\begin{abstract}
The constant normal stiffness (CNS) boundary condition is more representative for the underground engineering, in which the shear-induced dilation is restricted by surrounding rocks, resulting in an increase in the normal stress. Therefore, the use of CNS boundary conditions in the research of shear-slip failure of underground rock engineering is more in line with the actual situation. Taking the instability and failure of surrounding rock in underground engineering as the background, the present study introduces the engineering background of CNS boundary conditions and the research progress on shear characteristics of rock joints under CNS boundary conditions. Three key directions for future research are proposed based on the latest research results of shear characteristics of rock joint under CNS boundary conditions: (1) developing a rock joint shear test system that can realize the function of "CNS boundary conditions + shear-seepage test + visualization"; (2) carrying out the shear tests of real rock joints under CNS boundary conditions based on 3D scanning and 3D carving technology; and (3) carrying out the shear tests of rock joint network under CNS boundary conditions.
\end{abstract}

\section{Introduction}

The stability of the rock mass is related to the construction, operation, and maintenance of important basic industrial content such as mining resources, transportation, water conservancy and hydropower, and national defense engineering [1-3].

However, the structural planes are widely presented in engineering rock masses which are formed by joints, cracks, and weak interlayers. The weak planes greatly weaken the strength and stability of the rock mass $[4,5]$. For the surrounding rock of deep underground engineering, the rock mass will undergo shear failure along the structural plane under the action of tectonic stress and seismic load. The shear-slip movement of the rock mass further weakens the bearing capacity and mechanical properties of the rock mass, thereby inducing serious roof deformation and collapse [6-10].
In addition to the lack of support measures in some projects, the most important reason for the shear slip of underground engineering rock mass is that the shearing effect of the structural plane is controlled by the complex geological environment and its own structural characteristics $[11,12]$. A unified understanding has not yet been formed academically due to the following reasons. First, the structural characteristics of the joint are one of the decisive factors affecting the shear characteristics of the joint while the previous studies mainly focused on single joints but lacked in-depth discussion on the shear characteristics of complex joint network structures [13, 14]. Second, most scholars currently use similar materials (high-strength cement, gypsum, and so on) to replicate natural joints while there are still big differences between samples poured with similar materials and natural rocks in terms of brittleness and mechanical properties. In addition, the constant normal load (CNL) boundary condition is still used in a large 
number of studies on the shear-slip problems of deep underground engineering, which leads to overestimation of the dilatancy of joints. For the case of deep underground, constant normal stiffness (CNS) boundary conditions are more applicable than CNL because the normal stress that is applied perpendicular to the shear direction is not a constant value $[8,15-19]$, while determined by the stiffness of surrounding rock (Figure 1).

The present study concludes the future research direction of shear characteristics of rock joints under CNS boundary conditions by summarizing and analyzing the research progress in four aspects: CNS testing machine, roughness characterization of structural plane, shear strength of rock joints under CNL boundary conditions, and shear behavior of rock joints under CNS boundary conditions. The research results will provide reference for the follow-up research.

\section{Research Status of Shear Behavior of Rock Joints}

Since the 1960s, the shear characteristics of joint planes began to receive attention and research from scholars because the engineering geological disasters caused by the shear slip of joint surface are constantly emerging. Previous research results show that the key factors affecting the shear strength of joint surface mainly include two aspects: one is internal factors, including rough undulation characteristics of joint surface, filling characteristics, and mechanical properties of joint surface; the other is the external factors, such as the stress state of the joint surface and the boundary conditions. This paper focuses on the development trend of the shear behavior of rock joints under the CNS boundary conditions. Therefore, the research and development status of the CNS testing machine, the characterization of structural surface roughness, the shear strength of rock joints under the CNL boundary conditions, and the shear behavior of rock joints under the CNS boundary conditions are listed in detail.

2.1. Research Progress of CNS Testing Machine. In 1985, Indraratna et al. [20-22] developed a set of equipment that can conduct the shear test of rock joints under CNS boundary conditions at the University of Wollongong, Australia (Figure 2(a)). The shear testing machine uses a set of springs to simulate the normal stiffness of the surrounding rock, and the normal stiffness is $8.5 \mathrm{kN} / \mathrm{mm}$, which can be adjusted by replacing the springs.

In 2000, Jiang et al. [17, 23, 24] of Nagasaki University in Japan developed a new type of servo-controlled shearing instrument using automated numerical control technology and virtual instruments (Figure 2(b)). Compared with the previous CNS shearing instrument, the advantages of this testing machine lie in the following three aspects: first, it improves the accuracy of the test results; second, the change of the normal stiffness no longer requires cumbersome replacement the spring, which can be set through computer input; third, the test plan can be adjusted at any time; for example, the boundary conditions of CNL and CNS can be switched at will during the shear test. In 2006, Jiang et al.
$[6,14,26]$ of Nagasaki University in Japan improved the previous equipment and developed a shear-seepage testing machine for rock joints. The testing machine realizes the coupling test of shear and seepage of rock joint under the boundary conditions of CNL and CNS. The testing machine is mainly composed of electro-hydraulic servo system unit, load and displacement measurement and control unit, shear loading unit, water supply, sealing and measuring device, and visualization system equipment. In 2008, Zhang et al. of Tsinghua University in China developed a large-scale threedimensional soil-structure interface testing machine [27]. The testing machine has the advantages of high loading capacity and large cross section. The testing machine can provide CNL, constant normal displacement, CNS, and other boundary conditions through the servo control system. In 2008, Belem et al. [28-30] at the University of Quebec in Canada developed a servo-controlled shearing instrument. The testing machine not only realizes the shear test under different boundary conditions (CNL, CNS, and constant normal displacement) but also realizes the cyclic shear test of rock joints. In 2018, Gui et al. [25] of Tongji University in China developed a novel multifunctional shear-flow coupled test system for rock joints (Figure 2(c)). The developed test system can carry out the shear-seepage test of rock joints under CNL, CNS, and constant normal displacement boundary conditions.

\subsection{Research Progress on Characterization of Structural} Surface Roughness. The evaluation of structural surface roughness is the basis for studying joint shear behavior. The rapid and accurate quantitative evaluation of the roughness of structural surface is conducive to the evaluation of shear strength of structural plane and provides scientific basis for the stability evaluation of engineering rock mass in the follow-up and finally serves the engineering practice. Myers [31] proposed the concept of $\mathrm{Z} 2$ and gave the corresponding calculation formula to quantitatively describe the roughness of the structural surface (Equation (1). Mandelbrot [32] calculated the fractal dimension based on fractal theory to evaluate the joint roughness coefficient (JRC). Barton and Choubey [33] proposed 10 standard contour lines for structural surfaces and stipulated that the value range of JRC is 0-20. Sayles and Thomas [34] proposed the structure function SF (Equation (2)); EI-Soudani [35] proposed the ratio of the true length of the fracture surface to its projected length (Equation (3)) Subsequently, scholars established corresponding formulas for calculating JRC based on the abovementioned statistical parameters of joint contours $[36,37]$ (Equations (4) and (5)). In addition, Xie et al. [38] proposed the empirical relationship between contour fractal dimension and JRC. Du et al. [39] summarized the anisotropy, heterogeneity, nonuniformity, and size effect characteristics of joint roughness coefficients based on extensive investigation of joint surface morphology and perfected the comprehensive evaluation method of joint shear strength. Liu et al. [40] found that JRC of rock joints could not be accurately estimated by using only a single statistical parameter and put forward a classified and weighted fitting 


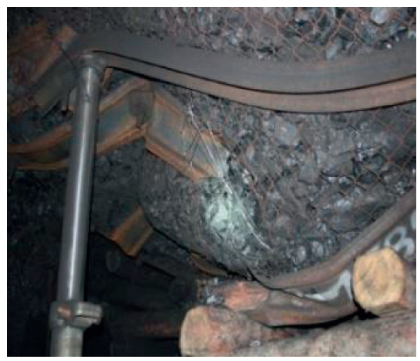

(a)

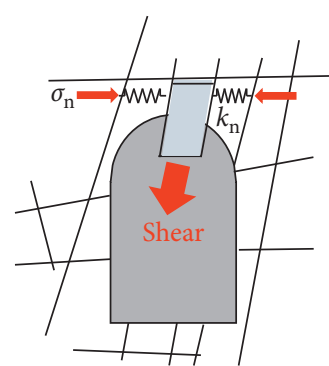

(b)

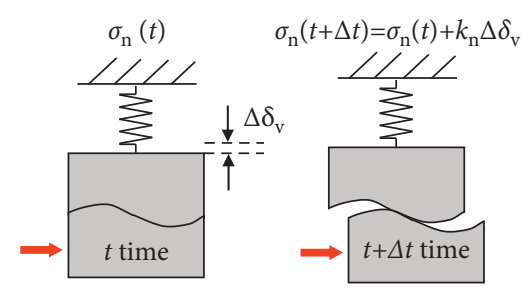

(c)

FIGURE 1: Joint shear-slip failure in deep underground engineering. (a) Coal mine roof deformation. (b) Roadway roof shear failure. (c) Joint CNS shearing.

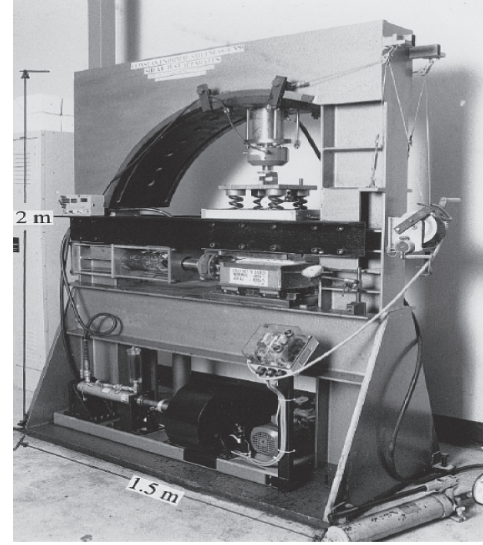

(a)

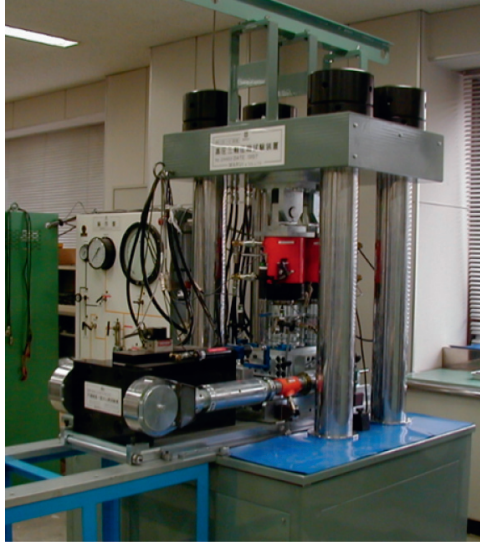

(b)

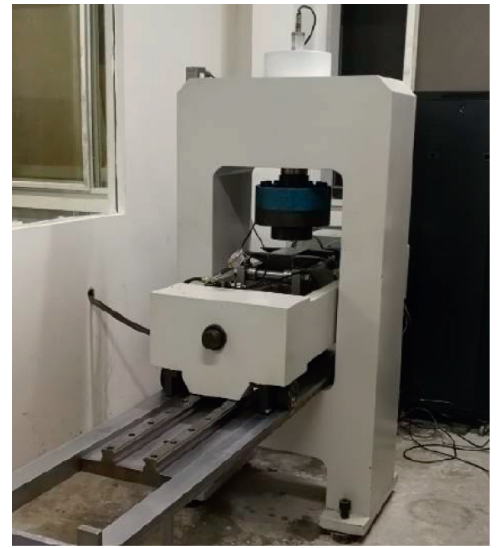

(c)

FIGURE 2: CNS shearing instrument. (a) CNS shearing instrument of Wollongong University, Australia [20-22]. (b) CNS shearing instrument of Nagasaki University, Japan $[17,23,24]$. (c) A novel multifunctional shear-flow coupled test system for rock joints of Tongji University [25].

formula to estimate the JRC (Equations (6)). The above research has important guiding significance for the study of joint shear behavior.

$$
\begin{aligned}
Z_{2} & =\left[\frac{1}{L} \int_{x=0}^{x=L}\left(\frac{\mathrm{d} y}{\mathrm{~d} x}\right)^{2} \mathrm{~d} x\right]^{1 / 2}=\left[\frac{1}{L} \sum_{i=1}^{n-1} \frac{\left(y_{i+1}-y_{i}\right)^{2}}{x_{i+1}-x_{i}}\right]^{1 / 2}, \\
\mathrm{SF} & =\frac{1}{L} \sum_{i=1}^{n-1}\left(y_{i+1}-y_{i}\right)^{2}\left(x_{i+1}-x_{i}\right) \\
R_{p} & =\frac{1}{L} \sum_{i=1}^{n-1}\left[\left(x_{i+1}-x_{i}\right)^{2}+\left(y_{i+1}-y_{i}\right)^{2}\right]^{1 / 2}, \\
\mathrm{JRC} & =32.2+32.47 \log Z_{2}, \\
\mathrm{JRC} & =37.28+16.58 \operatorname{logSF}, \\
\mathrm{JRC} & =16.09 \log Z_{2}^{1 s t}+12.70 \log Z_{2}^{2 n d}+33.75,
\end{aligned}
$$

where xi and zi represent the coordinates of the joint surface profile and $M$ is the number of sampling points along the length of a joint surface.
2.3. Research Progress on Shear Strength of Rock Joints under CNL Boundary Conditions. The shear effect of rock joints under CNL boundary conditions has been fully studied and developed for a long time since CNL boundary conditions are easy to implement in the laboratory. In 1966, Patton [41] proposed a bilinear model based on the shear test of regular zigzag joints, the model explaining the control effect of structural surface morphology on its shear strength. Since then, many scholars have carried out research on the shear strength model of the joint surface to serve engineering practice, i.e., Jaeger [3] proposed the shear effect model; Barton and Choubey [33] proposed the JRC-JCS model on the basis of summarizing a large number of tests to estimate the shear strength of structural plane under arbitrary normal stress (Equation (7)); Zhao et al. [42] considered that JMC had an effect on the peak shear stress of joints and proposed the JRC-JMC model (Equation (8)); Grasselli et al. [43] proposed the Grasselli model in three-dimensional scale; Wang et al. [44] proposed a shear strength model of rough structural plane considering shear rate based on the test results and JRC-JCS model (Equation (9)). In addition, Nagayama [45] et al., Li et al., [46], and Liu et al. [40] studied the influence of roughness, joint spacing, joint dip angle, and shear directivity on the shear mechanical properties of rock 

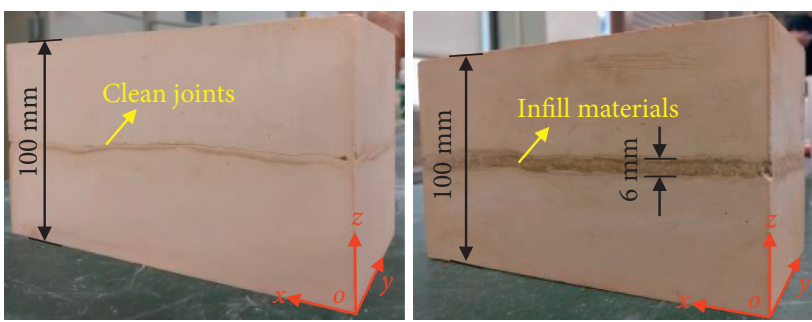

(a)

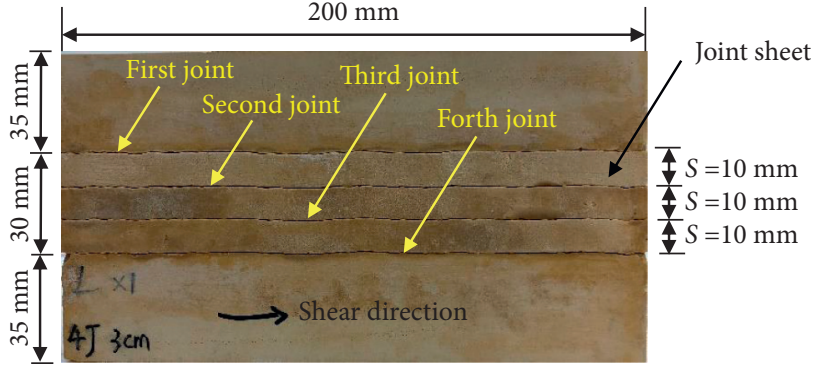

(b)

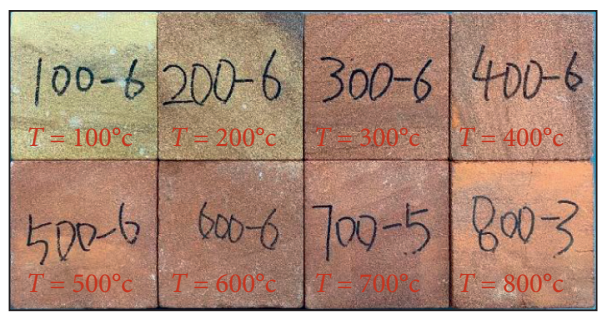

(c)

Figure 3: Specimens of latest studies. (a) Specimens of Han et al. 2020 [48]. (b) Specimens of Huang et al. 2021 [49]. (c) Specimens of Yin et al. 2021 [50].

joint and proposed the corresponding shear strength models.

$$
\begin{aligned}
& \tau=\sigma_{n} \tan \left[\mathrm{JRClog}\left(\frac{\mathrm{JCS}}{\sigma_{n}}\right)+\phi_{b}\right], \\
& \tau=\sigma_{n} \tan \left[\mathrm{JRC} \cdot \mathrm{JMC} \cdot \log _{10}\left(\frac{\mathrm{JCS}}{\sigma_{n}}\right)+\phi_{r}\right], \\
& \tau=0.982 \sigma_{n} \tan \left[4.970(\mathrm{JRC})^{0.475} \log \left(\frac{\mathrm{JCS}}{\sigma_{n}}\right)+\phi_{b}\right] \times v^{-0.06},
\end{aligned}
$$

where $\sigma \mathrm{n}$, JCS, $\varphi \mathrm{b}(\varphi \mathrm{r})$, and $v$ represent the normal stress, joint compressive strength, basic friction angle, and shear velocity, respectively.

2.4. Research Progress on Shear Behavior of Rock Joints under CNS Boundary Conditions. Indraratna et al. [20, 47] first developed a CNS testing machine and proposed an equation suitable for predicting the shear stress of regular serrated joints based on the energy conservation equation and Fourier series. Jiang et al. [24] developed a new type of servocontrolled shearing instrument using automated numerical control technology and virtual control technology and revealed the shear strength, volume expansion mechanism, and energy change law of different rough joint surfaces in the shearing process of rock joints through laboratory experiments. Then, Jiang et al. [17] developed a shear-seepage testing machine for rock joints under the CNS boundary conditions and carried out the relevant research on the hydraulic coupling characteristics in the shear process. In addition, the shear behavior of joints under CNS boundary conditions has been further studied and developed with the support of the abovementioned equipment. For example, Han et al. [48] carried out a cyclic shear test of rough joints under CNS boundary conditions and revealed the characteristics of joints such as shear stress, dilatancy, surface wear, and acoustic emission response (Figure 3(a)); Huang et al. [49] studied the mechanical behaviors of artificial samples containing multiple parallel joints during shearing under CNS conditions (Figure 3(b)); Yin et al. [50] studied shear mechanical responses of sandstone exposed to high temperature under CNS boundary conditions (Figure 3(c)).

\section{Discussion and Conclusion}

The development of the CNS testing machine can be roughly divided into three stages. First stage: the testing machine uses springs to simulate the stiffness of the surrounding rock. The above type of testing machine first realizes CNS boundary conditions, while the disadvantages are that the test accuracy is low and the normal stiffness of the test machine is inconvenient to adjust. Second stage: the testing machine uses a servo to control the normal stiffness, which is a revolutionary innovation compared with the first stage. This type of testing machine no longer uses springs to simulate the stiffness of the surrounding rock but develops a computer real-time feedback system to achieve real-time control of the normal stiffness of the testing machine by the computer. Third stage is the shear-seepage coupling test system. This type of testing machine realizes model testing under more complex conditions. The principle of the third stage testing system is to add a seepage system and a visualization system to the second stage testing machine.

Analyzing the research progress of structural surface roughness characterization, it can be found that there are few studies on the use of 3D scanning and 3D carving technology to replicate the original rock structural surface, especially the 
research on applying 3D scanning and 3D carving technology to the shear failure of surrounding rock in deep rock engineering is very rare.

Through the analysis of the research progress of rock joint shear strength under CNL boundary conditions, it can be found that most of the current studies are based on the simplification of joint surface morphology and stress state and do not consider the influence of real joint surface characteristics and the influence of surrounding rock on joint deformation. Therefore, the shear strength prediction model of joints under CNL boundary conditions is only suitable for shallow buried engineering or rock slope engineering without bolt.

In terms of the shear behavior of rock joints under CNS boundary conditions, the previous studies have reflected the shear mechanical properties of rock joints under CNS boundary conditions, including shear strength, dilatancy, joint surface damage, and so on. However, most of the research studies on rock joint shear under CNS boundary conditions are limited to the study of a single joint or the use of similar materials for model pouring. In addition, most of the joints are regular serrated joints. It is worth noting that there are two problems in the above research: one is that joints do not exist in isolation in rock mass, and they are often widely distributed in rock mass in the form of network; the other is that the model poured with similar materials is quite different from natural rock in brittleness and mechanical properties.

Based on the research progress of shear behavior of rock joints under CNS boundary conditions, three important directions for future research are proposed: (1) developing a rock joint shear test system that can realize the function of "CNS boundary conditions + shear-seepage test + visualization"; (2) carrying out the shear tests of real rock joints under CNS boundary conditions based on 3D scanning and 3D carving technology; and (3) carrying out the shear tests of rock joint network under CNS boundary conditions.

\section{Conflicts of Interest}

The author(s) declare that there are no conflicts of interest regarding the publication of this article.

\section{Acknowledgments}

This study was partially funded by the National Natural Science Foundation of China (Grant no. 42002275) and Zhejiang Provincial Natural Science Foundation of China (Grant nos. LQ21E040003 and LQ21D020001).

\section{References}

[1] J. Zhao, "Joint surface matching and shear strength part A: joint matching coefficient (JMC)," International Journal of Rock Mechanics and Mining Sciences, vol. 34, no. 2, pp. 173-178, 1997.

[2] I. W. Yeo, M. H. De Freitas, and R. W. Zimmerman, "Effect of shear displacement on the aperture and permeability of a rock fracture," International Journal of Rock Mechanics and Mining Sciences, vol. 35, no. 8, pp. 1051-1070, 1998.

[3] J. C. Jaeger, "Friction of rocks and stability of rock slopes," Géotechnique, vol. 21, no. 2, pp. 97-134, 1971.

[4] M. E. Plesha, "Constitutive models for rock discontinuities with dilatancy and surface degradation," International Journal for Numerical and Analytical Methods in Geomechanics, vol. 11, no. 4, pp. 345-362, 1987.

[5] L. Jing, O. Stephansson, and E. Nordlund, "Study of rock joints under cyclic loading conditions," Rock Mechanics and Rock Engineering, vol. 26, no. 3, pp. 215-232, 1993.

[6] T. Koyama, I. Neretnieks, and L. Jing, "A numerical study on differences in using Navier-Stokes and Reynolds equations for modeling the fluid flow and particle transport in single rock fractures with shear," International Journal of Rock Mechanics and Mining Sciences, vol. 45, no. 7, pp. 1082-1101, 2008.

[7] R. Liu, C. Wang, B. Li, Y. Jiang, and H. Jing, "Modeling linear and nonlinear fluid flow through sheared rough-walled joints taking into account boundary stiffness," Computers and Geotechnics, vol. 120, Article ID 103452, 2020.

[8] S. Thirukumaran, B. Indraratna, E. T. Brown, and P. K. Kaiser, "Stability of a rock block in a tunnel roof under constant normal stiffness conditions," Rock Mechanics and Rock Engineering, vol. 49, no. 4, pp. 1587-1593, 2016.

[9] B. Li, Y. Mo, L. Zou, R. Liu, and V. Cvetkovic, "Influence of surface roughness on fluid flow and solute transport through 3d crossed rock fractures," Journal of Hydrology, vol. 582, Article ID 124284, 2020.

[10] Y. Zhou, D. J. Zhao, B. Li, H. Y. Wang, Q. Q. Tang, and Z. Z. Zhang, "Fatigue damage mechanism and deformation behaviour of granite under ultrahigh-frequency cyclic loading conditions," Rock Mechanics and Rock Engineering, 2021.

[11] D. D. Kana, D. J. Fox, and S. M. Hsiung, "Interlock/friction model for dynamic shear response in natural jointed rock," International Journal of Rock Mechanics and Mining Science \& Geomechanics Abstracts, vol. 33, no. 4, pp. 371-386, 1996.

[12] D. J. Fox, D. D. KaÑa, and S. M. Hsiung, "Influence of interface roughness on dynamic shear behavior in jointed rock," International Journal of Rock Mechanics and Mining Sciences, vol. 35, no. 7, pp. 923-940, 1998.

[13] Y. Li, W. Wu, and B. Li, "An analytical model for two-order asperity degradation of rock joints under constant normal stiffness conditions," Rock Mechanics and Rock Engineering, vol. 51, no. 5, pp. 1431-1445, 2018.

[14] B. Li, Y. Jiang, T. Koyama, L. Jing, and Y. Tanabashi, "Experimental study of the hydro-mechanical behavior of rock joints using a parallel-plate model containing contact areas and artificial fractures," International Journal of Rock Mechanics and Mining Sciences, vol. 45, no. 3, pp. 362-375, 2008.

[15] S. Saeb and B. Amadei, "Modelling joint response under constant or variable normal stiffness boundary conditions," International Journal of Rock Mechanics and Mining Science \& Geomechanics Abstracts, vol. 27, no. 3, pp. 213-217, 1990.

[16] S. Saeb and B. Amadei, "Modelling rock joints under shear and normal loading," International Journal of Rock Mechanics and Mining Science \& Geomechanics Abstracts, vol. 29, no. 3, pp. 267-278, 1992.

[17] Y. Jiang, B. Li, and Y. Tanabashi, "Estimating the relation between surface roughness and mechanical properties of rock joints," International Journal of Rock Mechanics and Mining Sciences, vol. 43, no. 6, pp. 837-846, 2006.

[18] R. Liu, S. Lou, X. Li, G. Han, and Y. Jiang, “Anisotropic surface roughness and shear behaviors of rough-walled plaster joints under constant normal load and constant normal stiffness 
conditions," Journal of Rock Mechanics and Geotechnical Engineering, vol. 12, no. 2, pp. 338-352, 2020.

[19] B. Meng, H. Jing, S. Yang, Y. Wu, Y. Wang, and Y. Huang, "Experimental investigation on shear behavior of intact sandstones under constant normal stiffness conditions," International Journal of Geomechanics, vol. 21, no. 2, Article ID 04020259, 2021.

[20] B. Indraratna, S. Thirukumaran, E. T. Brown, and S.-P. Zhu, "Modelling the shear behaviour of rock joints with asperity damage under constant normal stiffness," Rock Mechanics and Rock Engineering, vol. 48, no. 1, pp. 179-195, 2015.

[21] B. Indraratna, A. Haque, and N. Aziz, "Shear behaviour of idealized infilled joints under constant normal stiffness," Géotechnique, vol. 49, no. 3, pp. 331-355, 1999.

[22] B. Indraratna, N. I. Aziz, and A. Dey, "Behaviour of joints containing clay infill under constant normal stiffness, with and without bolting," Proceedings of the Institution of Civil Engineers - Geotechnical Engineering, vol. 149, no. 4, pp. 259-267, 2001.

[23] Y. Jiang, Y. Tanabashi, and T. Mizokami, "Shear behavior of joints under constant normal stiffness conditions," in Proceedings of the Second Asian Rock Mechanics Symposium, Beijing, China, September 2001.

[24] Y. Jiang, J. Xiao, Y. Tanabashi, and T. Mizokami, "Development of an automated servo-controlled direct shear apparatus applying a constant normal stiffness condition," International Journal of Rock Mechanics and Mining Sciences, vol. 41, no. 2, pp. 275-286, 2004.

[25] Y. Gui, C. Xia, W. Ding, X. Qian, and S. Du, "Hydraulic characteristics of rough joints under coupled shear-flow conditions: an experimental study," Rock Mechanics and Rock Engineering, vol. 53, no. 7, pp. 3341-3352, 2020.

[26] X. Xiong, B. Li, Y. Jiang, T. Koyama, and C. Zhang, "Experimental and numerical study of the geometrical and hydraulic characteristics of a single rock fracture during shear," International Journal of Rock Mechanics and Mining Sciences, vol. 48, no. 8, pp. 1292-1302, 2011.

[27] J. M. Zhang, W. J. Hou, G. Zhang, and D. K. Feng, "Development of a 3D soil-structure interface test apparatus and its application," Chinese Journal of Geotechnical Engineering, vol. 30, no. 6, pp. 889-894, 2008.

[28] T. Belem, F. Homand-Etienne, and M. Souley, "Quantitative parameters for rock joint surface roughness," Rock Mechanics and Rock Engineering, vol. 33, no. 4, pp. 217-242, 2000.

[29] T. Belem, M. Souley, and F. Homand, "Modeling surface roughness degradation of rock joint wall during monotonic and cyclic shearing," Acta Geotechnica, vol. 2, no. 4, pp. 227-248, 2007.

[30] T. Belem, M. Souley, and F. Homand, "Method for quantification of wear of sheared joint walls based on surface morphology," Rock Mechanics and Rock Engineering, vol. 42, no. 6, pp. 883-910, 2009.

[31] N. O. Myers, "Characterization of surface roughness," Wear, vol. 5, no. 3, pp. 182-189, 1962.

[32] B. Mandelbrot, "How long is the coast of Britain? Statistical self-similarity and fractional dimension," Science, vol. 156, no. 3775, pp. 636-638, 1967.

[33] N. Barton and V. Choubey, "The shear strength of rock joints in theory and practice," Rock Mechanics Felsmechanik $M$ canique des Roches, vol. 10, no. 1-2, pp. 1-54, 1977.

[34] R. S. Sayles and T. R. Thomas, "The spatial representation of surface roughness by means of the structure function: a practical alternative to correlation," Wear, vol. 42, no. 2, pp. 263-276, 1977.
[35] S. M. El-Soudani, "Profilometric analysis of fractures," Metallography, vol. 11, no. 3, pp. 247-336, 1978.

[36] R. Tse and D. M. Cruden, "Estimating joint roughness coefficients," International Journal of Rock Mechanics and Mining Science \& Geomechanics Abstracts, vol. 16, no. 5, pp. 303-307, 1979.

[37] N. H. Maerz, J. A. Franklin, and C. P. Bennett, "Joint roughness measurement using shadow profilometry," International Journal of Rock Mechanics and Mining Science \& Geomechanics Abstracts, vol. 27, no. 5, pp. 329-343, 1990.

[38] H. Xie, J. Zhu, T. Zhou, K. Zhang, and C. Zhou, "Conceptualization and preliminary study of engineering disturbed rock dynamics," Geomechanics and Geophysics for Geo-Energy and Geo-Resources, vol. 6, no. 2, p. 34, 2020.

[39] S. G. Du, Y. J. Hu, and X. F. Hu, "Generalized models for rock joint surface shapes," Science World Journal, Article ID 171873, 2014

[40] X. G. Liu, W. C. Zhu, Q. L. Yu, S. J. Chen, and R. F. Li, "Estimation of the joint roughness coefficient of rock joints by consideration of two-order asperity and its application in double-joint shear tests," Engineering Geology, vol. 220, pp. 243-255, 2017.

[41] F. Patton, "Multiple modes of shear failure in rock," Proceeding of the1st Congress of International Society of Rock Mechanics, Lisbon, Portugal, September 1966.

[42] J. Zhao, "Joint surface matching and shear strength part B: JRC-JMC shear strength criterion," International Journal of Rock Mechanics and Mining Sciences, vol. 34, no. 2, pp. 179-185, 1997.

[43] G. Grasselli, "Shear strength of rock joints based on quantified surface description," in ISRM International Symposium/3rd Asian Rock Mechanics Symposium (ARMS), Kyoto, Japan, November 2004.

[44] G. Wang, X. Zhang, Y. Jiang, X. Wu, and S. Wang, "Ratedependent mechanical behavior of rough rock joints," International Journal of Rock Mechanics and Mining Sciences, vol. 83, pp. 231-240, 2016.

[45] I. Nagayama, H. Norimatsu, and H. Katahira, "Influences of dip and shearing strength of joints on shearing strength of rock mass," in Proceedings of the 9th Japan Symposium on Rock Mechanics, Kyoto, Japan, September 1994.

[46] B. Li, Y. Jiang, T. Mizokami, K. Ikusada, and Y. Mitani, "Anisotropic shear behavior of closely jointed rock masses," International Journal of Rock Mechanics and Mining Sciences, vol. 71, pp. 258-271, 2014.

[47] B. Indraratna, H. S. Welideniya, and E. T. Brown, "A shear strength model for idealised infilled joints under constant normal stiffness," Géotechnique, vol. 55, no. 3, pp. 215-226, 2005.

[48] G. Han, H. Jing, Y. Jiang, R. Liu, and J. Wu, "Effect of cyclic loading on the shear behaviours of both unfilled and infilled rough rock joints under constant normal stiffness conditions," Rock Mechanics and Rock Engineering, vol. 53, no. 1, pp. 3157, 2020.

[49] N. Huang, G. Han, R. Liu, and Y. Jiang, "Mechanical behaviors of artificial samples containing multiple parallel joints during shearing under constant normal stiffness conditions," Géotechnique Letters, vol. 11, no. 2, 2021.

[50] Q. Yin, J. Wu, C. Zhu, M. He, Q. Meng, and H. Jing, "Shear mechanical responses of sandstone exposed to high temperature under constant normal stiffness boundary conditions," Geomechanics and Geophysics for Geo-Energy and GeoResources, vol. 7, no. 2, p. 35, 2021. 